\title{
Enablers and inhibitors of efforts to reduce Scope 3 emissions - The case of an ODeL university
}

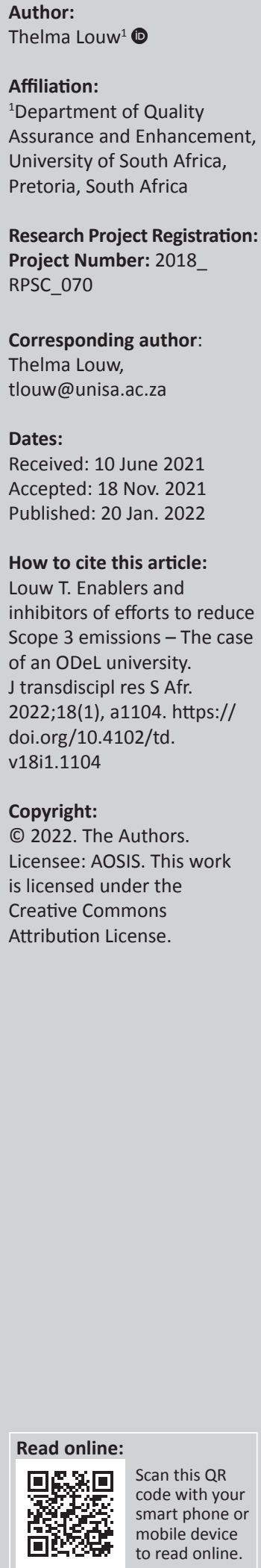

Background: The reconfiguration of the South African higher education landscape in 2003 and 2004 had a significant impact on the University of South Africa (UNISA) and Technikon SA (both distance education institutions) which merged to form the 'new' UNISA.

Aim: The aim of this conceptual study is to explore the extent to which the policies of the post-merger UNISA are enablers or inhibitors of efforts to reduce its Scope 3 carbon emissions.

Setting: Staff commuter patterns between the main campuses of UNISA and the policy environment that has an impact on such travel.

Methods: The aim is achieved by means of a case study methodology that considers the relevant policies of the university and applicable results of a 2018 UNISA staff travel demand survey to determine whether the policies are incongruous with the institution's attempts to reduce its carbon footprint in general, and its Scope 3 carbon emissions in particular. The impact of the coronavirus disease 2019 (COVID-19) pandemic on defining a 'new normal' for the university's operations, and the impact thereof on staff commuting, have been discussed.

Results: The study revealed that despite being an Open Distance E-Learning (ODeL) institution, the university has not put a coherent policy framework in place that undeniably supports its efforts to limit or reduce its Scope 3 carbon emissions. This was brought into stark focus by the measures the university was forced to put in place as a result of the COVID-19 lockdown regulations in South Africa, to ensure the continuation of its business.

Conclusion: The conclusions will assist UNISA - and other universities which have had to revisit their operations as a result of the COVID-19 pandemic - to define a true 'new normal'.

Keywords: travel demand management; Scope 3 emissions; telecommuting; distance education; sustainability.

\section{Introduction}

“" $[W]$ ork" is something you do and not a place you go to'.1

The most commonly used standard for reporting on greenhouse gas emissions (GHGs) is the Greenhouse Gas Protocol Corporate Standard. ${ }^{2}$ This protocol defines three 'scopes' of emission sources, namely: Scope 1 (direct emissions from sources owned or controlled by an organisation), Scope 2 (emissions from the generation of electricity, steam or heat purchased for use by the organisation), and Scope 3 (emissions which are a result of the business of the organisation and is not owned or controlled by such organisation). The carbon footprint of an organisation is the total amount of GHGs that is directly or indirectly caused by an organisation in its operations. ${ }^{3}$

The South African public higher education environment has undergone significant (albeit involuntary) change since the dawn of the new century - a process commonly referred to as the reconfiguration of the higher education landscape announced by the minister of Higher Education in 2003. The impact of this reconfiguration has not been similar for all higher education institutions (HEIs). In a series of mergers that took place in 2003 and January 2004, some institutions merged with neighbouring institutions, whilst other merging institutions were quite a distance apart. The latter was the case with the University of South Africa (UNISA) and Technikon SA (both distance education institutions) resulting in the establishment of the 'new' UNISA - an Open Distance E-learning (ODeL) institution. Each pre-merger institution boasted significant staff and student numbers. Both had campuses in all provinces, whilst their respective administrative hubs and/or main campuses were located approximately $70 \mathrm{~km}$ apart. This study focuses on staff travel between the main campuses of the new UNISA - for the purposes of working and attending meetings - and the way in which institutional policies 
have acted as enablers or inhibitors of Scope 3 emissions resulting from such travel.

As administrative and academic functions were realigned between the two main campuses, the workplaces of significant numbers of staff were reallocated. Although this reshuffle initially primarily involved unidirectional traffic (to the campus in Muckleneuk, Pretoria, South Africa), once the expansion of facilities on the Science Campus in Florida, Roodepoort, South Africa had concluded in 2013, the movement of staff between the campuses became bidirectional.

Prior to the merger, there had been an agreement with the local authority in Pretoria that afforded the institution the use of municipal buses to transport staff on various routes and from distances as far as $50 \mathrm{~km}$, to the campus. Although hundreds of staff members utilised this subsidised bus service, the agreement with the local authority was terminated in 2010, forcing all staff who had travelled on these buses to find alternative transport to the Muckleneuk campus. The alternative choice was private vehicles, resulting in severe parking shortages and traffic congestion at the Muckleneuk campus. To alleviate this congestion, the university purchased land adjacent to the campus to build a multi-storey parking facility - a project that has not progressed beyond the planning stages. Staff based at the Science Campus prior to the merger did not have any subsidised bus service to transport them to campus and had always arranged their own transport to and from work, and to this end primarily used private vehicles or taxis to reach the campus.

In 2018, the UNISA Sustainability Office and the Worldwide Fund for Nature - South Africa (WWF-SA) commissioned a research study to gauge commuter patterns amongst staff working at the Muckleneuk and Science campuses, respectively, and who were compelled to undertake intercampus commutes. The aim of the study was to arrive at a fundamental understanding of the complexities of staff commuting behaviours. The study sought to provide a basis for advising the management of the institution on effective interventions aimed at promoting responsible and sustainable transportation choices amongst staff, with a view to reducing Scope 3 emissions.

The researcher set out to explore the manner in which the policies of UNISA act as either enablers or inhibitors in managing the university's Scope 3 emissions. These policies become determinants of the travel patterns of staff to and from the two main campuses, as reflected in the findings of the WWF-SA study. To this end, the researcher will seek to discover whether these policies and practices are incongruous with the institution's attempts to reduce its carbon footprint in general, and its Scope 3 emissions in particular.

\section{Literature review}

Travel demand management (TDM) focuses not only on influencing the travel behaviours and mode choices of commuters or broadening their scope of options, but also on measures to reduce the need for travel. ${ }^{4}$ Yildirimoglu and
Ramezani ${ }^{5}$ found that limited changes in travel patterns, such as commuters departing $10 \mathrm{~min}$ earlier or later, result in betterperforming commuter networks, as congestion peaks are flattened. Motor vehicle traffic is one of the major and fastestgrowing sources of GHG emissions, ${ }^{6}$ with some companies reporting that it accounts for more than $50 \%$ of their carbon emissions. ${ }^{2,7}$ This may highlight inefficiencies in managing staff travel and indicate areas where there is room for improvement. ${ }^{8}$

Governments internationally conduct household travel surveys to inform their long-term infrastructure development plans. South Africa undertook such national surveys in 2003 and 2013. ${ }^{9}$ The 2013 survey cites the objective of the 2007 Public Transport Strategy of the national Department of Transport as being to 'achieve a significant shift of work trips from cars to public transport networks by 2020'. The third South African national household travel survey was undertaken in 2020, in the months before the national lockdown as a result of coronavirus disease 2019 (COVID-19). ${ }^{10}$ As these surveys included questions on education- and work-related travel, they were deemed relevant to this study.

Responsible business organisations (including universities) often evaluate their business processes ${ }^{11}$ and survey the travel patterns of their staff as part of their facilities management processes, ${ }^{12,13}$ in addition to using them to measure and manage their Scope 3 carbon emissions. ${ }^{14,15,16}$

\section{Universities as contributors to traffic congestion and Scope 3 carbon emissions}

Scope 3 carbon emissions, as the third of the scopes outlined in the Greenhouse Gas Protocol Corporate Standard, encompass emissions that are indirectly linked to an organisation's activities (which includes staff commuting). It was found ${ }^{2}$ that at $79 \%$ of emissions, Scope 3 emissions were the biggest and fastest-growing component of the total carbon footprint of De Montford University, with staff travel contributing three times more to carbon emissions than its closest rival, international student travel. Internationally, universities have put in place a range of TDM strategies on their campuses to alleviate congestion and reduce carbon emissions. ${ }^{12,17}$ Such measures include reducing the number of parking spaces, facilitating carpooling and providing staff and students with passes that allow them free access to local public transport. Of these, the freeride passes yielded the most marked behavioural change in terms of mode choice, whilst non-motorised transport was the least-preferred option. ${ }^{15,17}$

University staff and students are significant contributors to the general travel volumes and carbon emissions in those locations, with significant volume reductions being recorded during vacation periods. ${ }^{11,17,18}$ The dispersion effect of travel in other areas during vacation periods was not studied by these authors. It follows logically that locally and internationally, studies focusing on university campuses have found them to be intensely car-oriented environments. ${ }^{6}$ Campuses are generally not known as carbon-free hubs with 
ample access to green energy sources, such as solar-powered charging stations for electric vehicles. Traditional measures by governments to attempt to reduce vehicle use, such as increases in fuel prices, ${ }^{19}$ have had very little impact on the staff and students of those universities where alternative forms of transport (that are not dependent on fossil fuels) are generally unavailable or inaccessible, and where policies on telecommuting are not in place.

Millennials - a generation that is becoming a growing segment of the workforce of universities - in California, United States of America (USA) wait longer to apply for driver's licences, own fewer cars, drive less and prefer to use alternative modes of transport when travelling. ${ }^{20}$ As these authors ${ }^{20}$ noted, commuters develop habits in terms of their choice of travel modes - older commuters, for instance, prefer to travel by car. The latter confirms the results of other studies, ${ }^{6,21}$ which investigated students' travel patterns in Kerala, India. It was also found ${ }^{22}$ that persons with graduate degrees were more likely to telecommute more often than other respondents, with between $14 \%$ and $18 \%$ of participants in their study (who had at least a bachelor's degree) reporting that they telecommuted 'sometimes'.

\section{Telecommuting as a means of limiting Scope 3 carbon emissions}

Travel is a demand derived from people's need to perform an activity. ${ }^{21}$ Travel mode demands are more closely correlated to travel time, than to cost: commuters are willing to pay more for a quicker commute. ${ }^{17}$ This is understandable, given the limited flexibility of work schedules. ${ }^{5,13,23}$

Telecommuting (or working from home or remotely) is generally regarded as a sustainable and competitive alternative to daily commuting as it saves time and cost, minimises the environmental impact, improves labour flexibility and labour market access, and does not have adverse tax implications for employers or employees. ${ }^{24}$ The uptake of telecommuting by South African universities has, however, been very low, despite traffic congestion on and around university campuses nation-wide. Road transport is responsible for nearly threequarters of all transport energy consumption..$^{25}$ It has been found ${ }^{24}$ that telecommuting not only reduced travel demand but also eased peak-hour congestion - even on nontelecommuting days - given the increased flexibility of commuters' travel patterns. ${ }^{4}$ A commensurate reduction in fatal and less serious vehicle accidents has been predicted ${ }^{26}$ as a result of a decrease in the number of vehicles on the road, once people telecommute, highlighting the multi-faceted economic imperative for telecommuting as a mode of working. The reduction and dispersion effects of traffic volumes are identified as being amongst the key benefits of telecommuting. A further benefit of eliminating the daily commute is that it saves time. In a survey involving 454 respondents, ${ }^{27}$ a saving of between 2000 and 4000 employee hours per day was calculated for professionals who telecommute.

The rebound effect of telecommuting, ${ }^{24}$ namely an increase in other household travel, would not have been relevant during the South African COVID-19 lockdown period, as only essential travel was allowed, but it is worth considering as part of the post-lockdown 'new normal'.

\section{The impact of the Covid-19 pandemic on commuting}

A developed country such as the USA has had legislation in place to promote the development of telecommuting programmes since the 1990s. ${ }^{28}$ In South Africa, the first legislation on telecommuting appeared in the 2020 regulations promulgated as part of the national lockdown to curb the spread of COVID-19. The 'forced' changes in work patterns resulting from nation-wide and international lockdowns had a fundamental impact on all aspects of commuting and mode selection, confirming the contention ${ }^{29}$ that 'periods of disruption can often be catalysts for travel behaviour change'.

It has been found ${ }^{24}$ that telecommuting resulted in behavioural changes that contributed to the well-being of telecommuters, such as shared family responsibilities, which in turn positively affected the productivity of employees. Other authors ${ }^{30}$ found that more than $25 \%$ of their study's respondents reported increased productivity whilst working from home. In similar vein, World Wide Wor ${ }^{31}$ noted a massive $70 \%$ increase in productivity in South African companies which had a digital transformation strategy in place prior to the lockdown. There is currently only anecdotal evidence, however, that South African university employees who started telecommuting during the COVID-19 lockdown worked harder and longer hours than they normally do.

\section{Travel demand management study of UNISA staff}

As part of the literature informing this article, the UNISA TDM study $^{32}$ and its findings are an important source of secondary data. The TDM study investigated the transportation patterns amongst employees located at the two main campuses (Muckleneuk and Florida) of UNISA in 2018. The objective was to investigate the daily travel patterns and behaviour of staff commuting to and from the Muckleneuk and Florida campuses, respectively. As mentioned, such intercampus commuting primarily arose as a result of the relocation of staff workstations, following the merger of the two distance education institutions in 2004

Although emerging technologies have been used for travel data collection, with a growing interest in passive and global positioning system (GPS)-based techniques, ${ }^{33,34}$ the nature of the university's travel demand study did not lend itself to the use of such tools. An online questionnaire garnered the respondents' demographic information and included questions relating to a number of focus areas, namely:

- mode of transport most often used to commute to and from the campuses;

- car engine capacity and type of fuel used;

- duration, distance and estimated cost of commute;

- carpool or lift club opportunities and utilisation;

- intercampus staff commute shuttle usage; 
- satisfaction levels with the intercampus staff commute shuttle services and

- general staff perceptions regarding 'green travel'.

The research questionnaire was sent to all employees working at either the Muckleneuk or Science campuses of the university. The unusually high response rate of $96.6 \%$ could be an indication of how important the staff deemed the topic to be. The TDM study presented an opportunity for UNISA to evaluate its environmental performance and identify areas for environmental impact reduction ${ }^{3}$ relating to its Scope 3 emissions.

The development of a travel model based on a bottom-up approach - in other words, on the actual behaviour of individuals - has wide-ranging support. ${ }^{23}$ With that in mind, the following findings of the UNISA study ${ }^{32}$ are relevant to this article:

- There is an almost complete lack of telecommuting at the university. A total of $81.5 \%$ of respondents reported having to commute to their workplace five days a week; twothirds of them used their own vehicles for this purpose.

- More than $80 \%$ of the vehicles used, conveyed single occupants.

- Most shuttle users used private vehicles to reach the shuttle pickup points (adding to parking challenges) and a significant number $(23.7 \%)$ used public transport for this purpose.

- Nearly $80 \%$ of shuttle users did so for their convenience and to save on transport costs. As respondents reported that shuttle journeys usually take longer than a private car trip, this finding contradicts the assertion by another study ${ }^{17}$ that mode demand is more reactive to travel time than to cost.

- More than $80 \%$ of shuttle users reported being satisfied or extremely satisfied with the service.

\section{UNISA policy framework}

As indicated earlier, the reconfiguration of the South African higher education landscape in 2003 and 2004 had a significant impact on the travel patterns of staff at many of the affected HEIs. This includes the two distance education institutions which merged, as their administrative hubs and main campuses were located approximately $70 \mathrm{~km}$ apart. Despite its status as an ODeL institution, the relocation of administrative and academic functions between the two main campuses resulted in the relocation of the workplace of significant numbers of staff. Initially, the relocation was primarily unidirectional (to the Muckleneuk campus), but later to the Science campus as well. These forced changes added significant travel volumes to peak-hour traffic and carbon emissions on two of the country's busiest highways, which connect the two campuses. As a 'large employer' and an ODeL university, UNISA appeared to be in an excellent position to implement TDM and telecommuting programmes. After all, as another author ${ }^{14}$ suggested, larger organisations with more employees have more options when it comes to the deployment of TDM programmes.
The importance of policies for determining a university's sustainability trajectory is emphasised in another study. ${ }^{35}$ Immediately after the 2004 merger, UNISA instituted a shuttle service to ferry staff between the two main campuses (Muckleneuk and Science Campus) - in line with international trends for larger employers and universities aiming to reduce congestion and Scope 3 carbon emissions. ${ }^{15}$ The number of staff making use of this service daily attests to its effectiveness as a measure to limit the institution's Scope 3 emissions from staff travel, peak-hour traffic congestion and parking challenges. As indicated earlier, its efficiency was confirmed by respondents during the institution's travel demand study.

Employer policies have proven to be effective instruments for reducing congestion and Scope 3 emissions. ${ }^{13}$ Despite both being distance education institutions, neither of the premerger institutions had any telecommuting policy or practice in place prior to merging. This is not unusual even in developed countries, as $\mathrm{Zhu}^{36}$ indicates that nearly $90 \%$ of respondents in national household travel surveys in the USA in the early 2000s indicated that they did not have the option to telecommute.

The absence of significant policies on telecommuting continued after the merger, despite significant involuntary spatial changes in the commuting destinations of the relocated staff. Despite having a parking policy in place, ${ }^{37}$ which states that the university aims to become a carbon neutral organisation and will continually strive to improve its carbon emissions by embarking on initiatives to curb its carbon footprint (such as promoting lift club parking to limit the number of private vehicles used to commute to work and parking fees for allocated on-campus parking), congestion has remained highly problematic, particularly on the Muckleneuk campus. Access control systems do not limit staff vehicle access solely to those with an allocated parking bay. This results in excessive illegal parking on campus - a situation not uncommon around the world on university campuses. ${ }^{12}$ The only solution considered thus far by the university to resolve the problem of congestion and illegal parking on the Muckleneuk campus has been to plan the construction of additional multi-level parking facilities at great cost.

The first policy of the university that allowed some forms of telecommuting dealt with professors working from home. ${ }^{38}$ Although the concept was piloted from 2007, the policy only came into effect in $2011-7$ years after the merger. The objective of the policy was to increase research outputs whilst simultaneously alleviating office space constraints. It was applicable to academic staff members at the level of associate professor or full professor, employed by the institution for more than 3 years, and who boasted aboveaverage performance ratings. Applicants needed to have a performance agreement in place and had to declare that they would not work from 'an office established or maintained elsewhere' ${ }^{38}$ Approvals were subject to annual review and required five (5) hierarchical levels of consent. Ultimately, fewer than $10 \%$ of professors benefited from the policy. 
Although the policy was never revoked formally, the Executive Committee of the University's Council resolved in April 2019 that all professors working from home should be recalled and should return to campus on 01 June of that year, based on concerns regarding service delivery to students.

The only other relevant policy of the university pertains to official working hours. This policy, which is applicable to all staff, allows for flexibility of approximately $2 \mathrm{~h}$ at the beginning and end of the workday. Up to four hierarchical levels of approval are required for staff wishing to make use of these flexible working hours, by starting earlier or later than the official hours. As other authors ${ }^{3,12}$ pointed out, inflexible work schedules limit staff members' ability to avoid peak-hour travel and congestion.

\section{Methodology}

A case study research methodology was used. A case study is well suited to examine why and how phenomena occur in organisations, without disrupting the operations of such organisations. Using this methodology, the researcher explored the relevant literature on the topic of enablers, inhibitors and organisational practices regarding travel demand nationally and internationally at universities and other organisations. The researcher further examined the relevant policies and operations of the university to discover whether these are incongruous with attempts to reduce UNISA's carbon footprint and its Scope 3 emissions. The impact of the COVID-19 pandemic on defining a 'new normal' for the university's operations and staff commuting was explored, leading to recommendations for policy development that will enable a 'new normal'.

\section{Ethical considerations}

The use of the results of the travel demand survey as part of the literature for the case study was approved by the UNISA Professional Research Committee, Research Ethics Workgroup, reference number: 2018_PRC_REW_011.

\section{Discussion}

There is growing interest in the travel patterns associated with university campuses ${ }^{6}$ - metropolitan campuses in particular - as the decision of staff to use their own vehicles is motivated by matters such as the desire for greater mobility, flexibility, reliability, comfort and personalisation. ${ }^{39}$ These needs, which may be regarded as selfish, ${ }^{40}$ counters the positive relationship between reducing carbon emissions and enhancing organisational reputation. If a university wants to secure the long-term trust and acceptance of its stakeholders, it must be cognisant of its carbon emissions and consciously put measures in place to reduce its carbon footprint. ${ }^{3}$ Like other employers, universities have significant influence over the Scope 3 emissions resulting from staff travel and should not underestimate the power of their executive decisionmaking to achieve reduction objectives or targets within a short period of time. ${ }^{22}$
Universities are known as incubators of innovation ${ }^{41}$ and their staff members are generally highly educated and open to change. ${ }^{17}$ Such incubated knowledge should be nurtured and applied to the advantage of the university as well as local, provincial and national policymaking. ${ }^{41}$ Notably, authors ${ }^{15}$ found that educational facilities are less likely to participate in TDM programmes, and that worksites which lack good access to transit facilities (such as the Science Campus) are more likely to implement TDM programmes.

UNISA took a significant step in identifying and working towards sustainability goals by establishing a Sustainability Office in 2013. It is, to date, the only South African university to have taken this bold step which resulted in the development of master plans on waste, water, carbon emissions, alternative energy and energy efficiency. It has also played a significant role in the establishment of a Sustainability Community of Practice for all South African universities and approved institutional research such as the travel demand survey discussed above. It is, however, evident from the institutional policies that UNISA has been hesitant to include ecoefficiency principles that will significantly reduce its Scope 3 carbon emissions (such as telecommuting and active staff travel interventions) as permanent features of its business model. This is somewhat contradictory to its mission as an ODeL institution and is not in line with international trends at universities which are attempting to reduce the use of private vehicles and encourage reliance on other modes of transport. ${ }^{12}$ Some authors ${ }^{13}$ posited that the low uptake of (and even resistance to) telecommuting, on the part of employers, might be attributed to managers being afraid of losing control over employees, albeit that, in general, strict adherence to office hours does not relate positively to staff efficiency.

The COVID-19 pandemic should be seen as an opportunity to enter a re-organisation phase of innovation and creativity. ${ }^{42}$ This notion should be embraced by South African universities in general and Unisa as an ODeL institution in particular. For as long as the communities around the Science campus remain underserviced by public transport, staff located at, and commuting to and from that campus to the Muckleneuk campus, will have little alternative but to use private vehicles for their commute if they are not allowed to telecommute. This confirms the finding of studies ${ }^{23}$ that mode choice is strongly related to network variables.

It behoves Unisa to introduce and retain both 'hard' and 'soft' policies ${ }^{39}$ to reduce its Scope 3 carbon emissions, specifically by focusing on reducing staff travel as the most significant component of Scope 3 emissions. 'Hard' policies aim to reduce the attractiveness of travelling by car, whilst 'soft' policies emphasise the benefits of using other modes of travel - or not travelling at all, by relying on telecommuting. Limiting the commuter benefits provided by the employer, through financial disincentives such as increasing parking costs, have proven to encourage employees to change their commuting habits. ${ }^{43}$ In this regard, several authors ${ }^{12,17,39,43}$ 
found that subsidised public transport yielded a significant behavioural change amongst employees regarding mode choice. Other authors ${ }^{4}$ advised that combining as few as two small-scale travel behaviour changes is likely to have a bigger benefit than a single large-scale change with smaller uptake. Further indications are ${ }^{17}$ that a combination of travel demand measures is most effective; however, that will require significant policy changes and changes in travel time and cost to curb car use.

It was further found ${ }^{27}$ that commuters who met the description of 'professionals' were the single largest group to use single-occupancy vehicles, which is a notable problem on university campuses. ${ }^{2}$ The modal share of motor vehicles amongst university staff was found to be more than $60 \%,{ }^{17}$ making cars by far the preferred mode of transport. This is supported by lived evidence of congestion on the two main campuses of UNISA and other university campuses. Yet, during the COVID-19 lockdown, when telecommuting was forced on the institution by national lockdown regulations, and business continued largely unimpeded, the generally highly congested campus parking areas, roads and sidewalks were practically deserted.

\section{The 2020 COVID-19 pandemic as determinant of the 'new normal'}

The COVID-19 pandemic and resultant world-wide lockdowns forced countries and organisations (including universities) to review and reconsider most aspects of the way work is done. ${ }^{44}$ These authors ${ }^{44}$ noted that nearly half of their study's respondents reported being able to work from home during lockdown, and another author ${ }^{45}$ concluded that COVID-19 has caused 'an unprecedented shift in travel behaviour'. Some authors ${ }^{42}$ indicated that the pandemic marked a significant 'collapse of the human-earth system'. Globally, images were shared in the popular press of clear skies in what are generally highly polluted cities, and of previously polluted waterways and canals teeming with fish. These are indicators of the positive impact a significant reduction or complete cessation of the daily commute and other travel can have on the environment.

Preventive measures aimed at limiting the spread of the virus, including minimising (if not prohibiting) face-to-face interaction, ${ }^{46}$ are likely to remain in place at South African universities for the foreseeable future as part of the national strategy to curb the spread of infections. The success with which information and communications technologies (ICTs) have been used to ensure business continuity throughout most of the annual South African university cycle seems to indicate that there will be no returning to the way operations were conducted in the higher education sector pre-2020. This is the case with both residential and distance education institutions. Although the learning curve for the use of ICTs was arguably steeper at residential institutions, it was not insignificant at UNISA as it too had to refocus and upscale its ICT systems to enable staff to work from home to conclude the academic year.
The strides made in ICT applications at South African universities may influence the uptake of other technological advances, such as vehicle automation - something which some authors ${ }^{25}$ regarded as a possible solution to challenges such as the energy intensity of commuting by car, and parking constraints. Telecommuting and vehicle automationthrough automated car-sharing and the productive use of travel time in particular-could be regarded as complementary future technologies, particularly on days when a university's telecommuters need to be physically present on the campus.

It is also pointed out ${ }^{30,44}$ that a fear of contracting COVID-19 has resulted in a resurgence of private vehicle travel, with conditions such as depression and anxiety as a result of the pandemic increasing the likelihood of drivers making accidents. As most current vehicle commuters do not plan to change their transport mode ${ }^{47}$ it means that traffic congestion may be worse once travel restrictions are lifted, unless policies on telecommuting are adopted and implemented, wherever possible..$^{22}$ In South Africa, Gautrain in the economic heart of the country reported only about $14 \%$ of preCOVID-19 use when lockdown restrictions were eased, ${ }^{48}$ with the rail feeder buses down to $16 \%$ of pre-COVID-19 utilisation. In 2003, it took public transport numbers in Taipei, Taiwan, nearly 5 months after the last reported SARS death to return to pre-pandemic numbers. ${ }^{47}$

The post-COVID-19 'new normal' needs to be informed by Life Cycle Thinking (LCT) $)^{11}$ - a new normal that will be determined by aspirational thinking and the courage to discontinue workplace activities, such as the daily commute, that have been unmasked by the pandemic as either obsolete or no longer fit for the purpose. ${ }^{42}$ UNISA should critically reconsider the need for staff to commute between the Muckleneuk and Science campuses daily, given that both campuses are located in large metropolitan areas. The positive impact of telecommuting on traffic congestion and pollution in the metros concerned would be significant. ${ }^{28}$ This can contribute significantly to reducing the university's Scope 3 carbon emissions ${ }^{14}$ and curb single-occupancy car travel. $^{7}$

It was found ${ }^{20}$ that transit riders, who used public transport regularly to commute, showed the strongest support for environmental policies. The positive attitudes and intentions of university staff to adhere to sustainability principles and initiatives ${ }^{12}$ should be converted into actions, to significantly reduce the university's Scope 3 carbon emissions by means of a focused, enabling and environmentally conscious policy framework.

The 'forced' telecommuting resulting from the national lockdown regulations in South Africa fast-tracked UNISA's implementation of a digital transformation strategy, thus confirming the findings of other studies. ${ }^{22,31}$ Although the telecommuting was unplanned and unprecedented, it had no significant negative impact on the operations of the university. On the contrary, anecdotal information indicates that the 
university's operational costs decreased significantly and its ability to allow most staff to perform their functions remotely, together with the productivity benefits of telecommuting for the majority, was pushed to the forefront. The positive impact on the university's Scope 3 carbon emissions from reduced staff travel was also significant, as staff were prohibited from entering the campuses and required a permit from their senior manager to do so when such entry was unavoidable for business reasons.

\section{Conclusion}

It is clear from the prior discussion that despite its status as an ODeL institution, UNISA does not have a policy regime that can be regarded as an enabler of its efforts to reduce its Scope 3 carbon emissions. In line with international best practice 12 and with several studies indicating that close to $40 \%$ of companies intend to continue allowing their staff to telecommute after the lockdowns are lifted, ${ }^{30,31}$ it is recommended that policies be put in place that will allow academics and other employees of UNISA to continue to telecommute as far as possible. Although the ICT implication of such a policy change is significant, it does not entail anything outside its ODeL mandate that the university did not deal with fairly successfully whilst in lockdown. Office space constraints will be resolved immediately, with significant savings on rented office space. Owned office space can be made available to staff who need to travel to the main campuses occasionally, via an online booking system. A policy on telecommuting will likely have a positive impact on the recruitment strategy of the university as well, allowing it to attract the best possible skills regardless of where those skills reside within the country or the world.

For staff functions where telecommuting is not possible, the intercampus shuttle services and, more importantly, transit services to rail, etc. should be retained and even expanded where local authorities cannot be influenced to enhance existing transit routes past the campuses. This is feasible as $80 \%$ of UNISA shuttle users who participated in the TDM study reported that they did so for their convenience and to save on transport costs, and more than $80 \%$ reported being satisfied or extremely satisfied with the service. The university can ensure the attractiveness of such functional, safe, cost-effective and convenient alternative forms of transport to staff by fully or partially subsidising these forms of transport. As reported earlier, a significant number $(23.7 \%)$ of shuttle users used public transport to reach the shuttle pick-up point. With the Gautrain planning loyalty programmes and additional discounts for the youth in the form of a new student product and travel card 48 to boost its numbers as a result of the lockdown slump, it is opportune for the university to negotiate similar benefits for its staff. The subsidising of transit services and public transport can be funded from market-related on-campus parking fees on the Muckleneuk and Science campuses and from the leasing of land to the owner of the pay-parking facility on the Muckleneuk campus referred to elsewhere.
To eliminate on-campus congestion, it is suggested that access control at vehicle boom gates limits access to staff with allocated parking on the campus, thereby eliminating the excessive illegal parking on the Muckleneuk campus in particular. It is further recommended that the university leases the land it had previously earmarked for building additional parking facilities on the Muckleneuk campus to a developer for the construction of a safe park-and-pay facility. This will provide parking to visitors and telecommuting staff members who may have to access the campus from time to time. As indicated, the income generated from leasing this land to the developer can be used, amongst others, to subsidise public transport for staff members.

Once the critical decisions have been taken by those in positions mandated to do so, to develop and implement Scope 3 carbon emission-saving policies relating to telecommuting and other staff travel, buy-in can be ensured by crafting a compelling and relevant message to raise awareness of the need for these changes.

\section{Acknowledgements Competing interests}

The author declares that she has no financial or personal relationships that may have inappropriately influenced her in writing this article.

\section{Author's contributions}

T.L. is the sole author of this article.

\section{Funding information}

This research received no specific grant from any funding agency in the public, commercial or not-for-profit sectors.

\section{Data availability}

Data sharing is not applicable to this article as no new data were created or analysed in this study.

\section{Disclaimer}

The views and opinions expressed in this article are those of the author and do not necessarily reflect the official policy or position of any affiliated agency of the author, and the publisher.

\section{References}

1. Du Plessis G. Benefits can outweigh drawbacks in new workplace reality [homepage on the Internet]. Business Live 2020 [cited 2020 Aug 18]. Available from: http:// www.businesslive.co.za

2. Ozawa-Meida L, Brockway P, Letten K, Davies J, Fleming P. Measuring carbon performance in a UK university through a consumption-based carbon footprint: De Montford University case study. J Cleaner Production. 2013;56:185-198. https://doi.org/10.1016/j.jclepro.2011.09.028

3. Ruževičius J, Dapkus M. Methodologies for calculating the carbon footprint of small organizations. Environ Manag. 2018;19(167):112-117.

4. Hu X, Chiu Y, Shelton J. Development of a behaviourally induced system-optimal travel demand management system. J Intell Transport Syst. 2017;21(1):12-25. https://doi.org/10.1080/15472450.2016.1171151 
5. Yildirimoglu M, Ramezani M. Demand management with limited cooperation among travellers: A doubly dynamic approach. Transport Res Part B. 2020;132:267-284. https://doi.org/10.1016/j.trb.2019.02.012

6. Soria-Lara JA, Marquet $\mathrm{O}$, Miralles-Gausch C. The influence of location, socioeconomics and behaviour on travel-demand by car in metropolitan university campuses. Transport Res Part D. 2017:53:149-160. https://doi.org/10.1016/ j.trd.2017.04.008

7. Awanthi MGG, Navaratne CM. Carbon footprint of an organization: A tool for monitoring impacts on global warming. Procedia Engineering. 2018;212:729-735. https://doi.org/10.1016/j.proeng.2018.01.094

8. Raghuram C, Jayaraman R. Reducing the carbon footprint in the supply chain J Supply Chain Manag Syst. 2013;2(1):19-27.

9. Statistics South Africa (Stats SA). National household travel survey, 2013. Statistical release P0320. Pretoria: Statistics South Africa; 2014

10. Statistics South Africa. National household travel survey (NHTS) [homepage on the Internet]. [cited 2020 July 14]. Available from: http://www.statssa.gov. $\mathrm{za} / \mathrm{p} \mathrm{p}=12888$

11. Carvalho M, De Santana Freire R, De Brito AMVG. This is a chapter. In P. Grammelis, editor. Energy, transportation and global warming. Athens: Springer, 2016; p. 61-72.

12. Rotaris $L$, Danielis R. Commuting to college: The effectiveness and social efficiency of transportation demand management policies. Transport Policy. 2015;44:158-168. https://doi.org/10.1016/j.tranpol.2015.08.001

13. Yushimito WF, Holguin-Veras J, Gellona T. Firm's efficiency and the feasibility of incentives for flexitime adoption: A preliminary analysis of Chilean employer's response. Transport Lett. 2016;10(4):202-214. https://doi.org/10.1080/1942786 7.2016.1243297

14. Bermeo JF, Rodrigues VM, Alvarez MJ. Carbon footprint in corporate logistics operations in the food sector. Environ Qual Manage. 2018;27(3):135-146. https:// doi.org/10.1002/tqem.21535

15. Ko J, Kim D. Employer-based travel demand management program: Employer's choice and effectiveness. Transport Pol. 2017;59:1-9. https://doi.org/10.1016/ j.tranpol.2017.06.003

16. Olatunji OO, Akinlabi SA, Ayo OO, Madushele N, Adedeji PA, Fatoba SO. 2019. Drivers and barriers to competitive carbon footprint reduction in manufacturing supply chain: A brief review. Procedia Manuf. 2017;35:992-1000. https://doi. org/10.1016/j.promfg.2019.06.047

17. Barla P, Lapierre N, Daziano RA, Herrmann M. Reducing automobile dependency on campus transport demand management: A case study for Quebec City. Can Publ Pol. 2015;41(1):86-96. https://doi.org/10.3138/cpp.2013-018

18. Yu C, He Z. Analysing the spatial-temporal characteristics of bus travel demand using the heat map. J Transport Geogr. 2017;58:247-255. https://doi. org/10.1016/j.jtrangeo.2016.11.009

19. Khalilikhah M, Habibian M, Heaslip K. 2016. Acceptability of increasing petro price as a TDM pricing policy: A case study in Tehran. Transport Policy. 2017;45:136-144. https://doi.org/10.1016/j.tranpol.2015.09.014

20. Lee Y, Circella G, Mokhtarian PL, Guhathakurta S. Are millennials more multimodal? A latent-class cluster analysis with attitudes and preferences among millennial and Generation Y commuters in California. Trans
https://doi.org/10.1007/s11116-019-10026-6

21. Gopi KM, Tanenlimalil SG, Paul B. Total travel time analysis for students in a metropolitan area: A study from India. Int J Traffic Transport Eng. 2019;9(4): metropolitan area: A study from India. Int J Traffic

22. Shabanpour R, Golshani N, Tayarani M, Auld J, Mohammadian AK. Analysis of telecommuting behaviour and impacts on travel demand and the environment. Transport Res Part D. 2018;62:563-576. https://doi.org/10.1016/j.trd.2018.04.003

23. Ghasri M, Rashidi TH, Waller ST. Developing a disaggregate travel demand system of models using data-mining techniques. Transport Res Part A. 2017;105: 138-153. https://doi.org/10.1016/j.tra.2017.08.020

24. Kim S. Is telecommuting sustainable? An alternative approach to estimating the impact of home-based telecommuting on household travel. Int J Sustain Transport. 2017;11(2):72-85. https://doi.org/10.1080/15568318.2016.1193779

25. Wadud Z, MacKenzie D, Leiby P. Help or hindrance? The travel, energy and carbon impacts of highly automated vehicles. Transport Res Part A. 2016;86:1-18. https://doi.org/10.1016/j.tra.2015.12.001

26. Pirdavani A, Bellemans T, Brijs T, Kochan B, Wets G. Assessing the road safety impact of a teleworking policy by means of geographically weighted regression method. Transport Geogr. 2014;39:96-110. https://doi.org/10.1016/j.jtrangeo.2014.06.021
27. Jaff MM, Hamsa AAK. Estimating commute-travel implications of telecommuting by female employees in Kuala Lumpur, Malaysia. J Traffic Transport Eng. 2018;5(2):148-155. https://doi.org/10.1016/j.jtte.2018.03.001

28. Zhu P, Wang L, Jiang Y, Zhou J. Metropolitan size and the impacts of telecommuting on personal travel. Transportation. 2018:45:385-414. https://doi.org/10.1007/ s11116-017-9846-3

29. Hillcoat $C$. Reducing congestion during road works through travel demand Municip Eng. 2018;171(ME1):51-60. https://doi.org/10.1680/jmuen.16.00064

30. Singh V, Gupta K, Agarwal A, Chakrabarty N. Psychological impacts on travel behavior post-Covid-19 [homepage on the Internet]. WP \#33. Roorkee: Indian Institute of Technology; [cited 2020 Aug 19]. Available from: http://faculty.iir.ac. in/ amitfce/publications.html

31. World Wide Worx (for Cisco Systems). Remote working in South Africa, 2020 [homepage on the Internet]. [cited 2020 Aug 20]. Available from: http://www. worldwideworx.com/cisco-south-africa-the-secret-sauce-of-remote-working/

32. University of South Africa (UNISA). Transportation patterns and behaviour among Unisa staff working at the Unisa Pretoria and Science campuses. CR147. Pretoria: Bureau of Market Research; 2018.

33. Lee RJ, Sener IN, Mullins JA. III. An evaluation of emerging data collection technologies for travel demand modeling: From research to practice. Transport Lett. 2016;8(4):181-193. https://doi.org/10.1080/19427867.2015.1106787

34. Vij A, Shankari K. When is big data enough? Implications of using GPS-based surveys for travel demand analysis. Transport Res Part C. 2015;56:446-462. https://doi.org/10.1016/j.trc.2015.04.025

35. Molthan-Hill P, Robinson ZP, Hope A, Dharmasasmita A, McManus E. Reducing carbon emissions in business through responsible management education: Influence at the micro-, meso- and macro-levels. Int J Manag Educ. 2020;18(1): 1-15. https://doi.org/10.1016/j.ijme.2019.100328

36. Zhu P. Are telecommuting and personal travel complements or substitutes? Ann Reg Sci. 2012;48:619-639. https://doi.org/10.1007/s00168-011-0460-6

37. University of South Africa (Unisa). Parking policy. Pretoria: Unisa; 2015.

38. University of South Africa (Unisa). Policy: Professors working from home. Pretoria: Unisa; 2016.

39. Batur I, Koç M. Travel demand management (TDM) case study for social behavioural change towards sustainable urban transportation in Istanbul. Cities. 2017;69:20-35. https://doi.org/10.1016/j.cities.2017.05.017

40. Kilcullen $P$, Walsh J. Why it's a good time to reduce your company's carbon footprint. Eng J. 2010;64(8):328-331.

41. Robinson OJ, Tewkesbury A, Kemp S, Williams ID. Towards a universal carbon footprint standard: A case study of carbon management at universities. J Cleaner Prod. 2018;172:4435-4455. https://doi.org/10.1016/j.jclepro.2017.02.147

42. Lew AA, Cheer JM, Haywood M, Brouder P, Salazar NB. Visions of travel and tourism after the global Covid-19 transformation of 2020. Tourism Geogr. 2020;42(3):455-466. https://doi.org/10.1080/14616688.2020.1770326

43. Bueno PC, Gomez J, Peters JR, Vassallo JM. Understanding the effects of transit benefits on employees' travel behaviour: Evidence from the New York-New Jersey region. Transport Res Part A. 2017;99:1-13. https://doi.org/10.1016/j. tra.2017.02.009

44. Beck MJ, Hensher DA. Insights into the impact of Covid-19 on household travel and activities in Australia - The early days under restrictions. Transport Pol. 2020;96:76-93. https://doi.org/10.1016/j.tranpol.2020.07.001

45. Marsden G. Potential impact of the Covid-19 pandemic on the future of travel demand. Civil Eng. 2020;173(3):99. https://doi.org/10.1680/jcien.2020. 173.3.99

46. Oum TH, Wang K. Socially optimal lockdown and travel restrictions for fighting communicable virus, including Covid-19. Transport Pol. 2020;96:94-100. https:// doi.org/10.1016/j.tranpol.2020.07.003

47. Harrington DM, Hadjiconstantinou M. Changes in commuting behaviours in response to the Covid-19 pandemic in the UK [homepage on the Internet]. Leicester Diabetes Centre; [cited 2020 Sept 27]. Available from: https://osf.io/ Leicester Diab

48. Venter I. Gautrain set for big loss as ridership falls owing to Covid-19 [homepage on the Internet]. Engineering News [cited 2020 Aug 24]. Available from: http://www.engineeringnews.co.za 